\title{
IMAGENS DE VIGILÂNCIA E VIOLÊNCIA: UMA EDUCAÇÃO DOMESTICADORA E SUA SUPERAÇÃO
}

\section{SURVEILLANCE IMAGES AND VIOLENCE: A MANIPULATING EDUCATION AND ITS OVERCOMING}

George Ulysses Rodrigues de Sousa ${ }^{1}$

\section{RESUMO}

O presente memorial busca discorrer sobre o processo criativo da obra OQUEVEMOS. Além de tratar das escolhas estéticas e das metodologias de criação da obra, este trabalho pretende pôr em diálogo os conceitos filosóficos, artísticos e científicos que, reunidos diante de uma mesma proposta, contribuíram para a elaboração de OQUEVEMOS. A investigação sobre os conceitos de Aparelhamento, programação e jogo do Filósofo Vilém Flusser se entrelaça aos estudos de montagem e formalização de imagens técnicas e seus efeitos sobre o espectador.

Palavras-chave: Flusser. Aparelhamento. Imagem Técnica. Filosofia da Imagem.

\begin{abstract}
This memorial registers the creation process of the video-essay OQUEVEMOS. In addition to discourse with the aesthetic choices and methodologies of creation of the work, this memorial intends to create a dialogue between the philosophical, artistic and scientific concepts that, united before the same objective, contributed to the elaboration of OQUEVEMOS. Researches on Vilém Flusser's concepts of apparatus, programming and game are intertwined with the studies of montage and formalization of technical images and their effects on the spectator
\end{abstract}

Keywords: Flusser. Apparatus. Technical image. Philosophy of the image.

\section{INTRODUÇÃO}

As imagens das câmeras de vigilância nos atualizam da esfera onde ocorrem eventos alheios a nós. Codificam o mundo concreto e nos informam. Para falar de imagens e codificação do mundo, poderíamos analisar a televisão e sua construção de um sujeito coletivo (o sujeito-SE de Couchot), poderíamos falar das imagens de erotização infantil ou das terríveis imagens pornográficas que objetificam pessoas - mulheres, majoritariamente. Para falar de sujeito, entretanto, para entrar na intimidade, no ponto de vista único e subjetivo, escolhemos as imagens de vigilância, os dispositivos destas e de como eles se atualizam. A violência, que também inova em suas maneiras, precisa que o Aparelho a acompanhe - e vice-

${ }^{1}$ George Ulysses é Bacharel em Cinema e Audiovisual pelo Instituto de Cultura e Arte da Universidade Federal do Ceará. Estuda a Ontologia do objeto comunicacional e suas implicações na Arte, Educação e Política.

Revista Labor Fortaleza/CE, jul/dez 2018 nº 20, Vol. 01, pp. 145-161 ISSN 1983-5000 
versa. E teremos retratos fiéis de atos de agressão via internet em alta qualidade de imagem. E teremos a baixa qualidade das câmeras de vigilância de redes de supermercados que não ficam em uma caixa preta, mas nos corredores onde os clientes fazem compras para que vejam uma versão menos concreta de si, magicamente transformada em sujeito vigiado: imagem que irá nos domesticar também fisicamente - não podemos parecer ladrões diante das câmeras.

As imagens precisam ser vistas e revistas. E quando digo isto, quero fazer saber o poder que exercem. Importa muito à Violência que sua imagem seja natural, que sua imagem entre sem sutileza nas máquinas de visibilidade, a violência, bem como o vício, o ódio, o medo, precisa ser vista. É assim que nos domestica o Aparelho, é assim que a violência se torna íntima. A partir de nossos dispositivos nós podemos criar formas novas de perceber o mundo. Arlindo Machado, em seu O Sujeito na Tela (2001, p. 202), diz que "em cada época e no contexto de cada meio, nossos órgãos dos sentidos parecem ser 'educados' para se comportar de determinada maneira com relação aos estímulos que lhes são oferecidos": o que podemos entender então é que, independente de época, estamos sempre aparelhados. E se estávamos aparelhados enquanto desenvolvíamos o modo de visão suposto pela fotografia, por qual motivo não estaríamos agora, conectados como estamos, integrados ao mundo virtual, aos smartphones e às câmeras de vigilância? É de extrema importância percebermos como nos relacionamos com nossas máquinas de visão, como estamos vinculados ao regime de percepção imposto por elas e como podemos transvalorar isso, ressignificando os dispositivos de representação da realidade para, finalmente, nos tornarmos jogadores dentro desta sociedade aparelhada.

É interessante falar da Vigilância. Ou da Violência. Contudo, este trabalho se propõe a pensar, seguindo os pensamentos de Flusser, como "a história toda, política, arte, ciência, técnica, vai destarte sendo incentivada pelo aparelho, a fim de ser transcodada no seu oposto: em programa televisionado. O aparelho se tornou o motor da história.” (2011, p. 119). Não de maneira tão grandiosa como é sugerida pela citação, mas em uma esfera menor: como um evento é engolido pelo aparelho? A ideia de vigilância, violência e aparelhamento não estão intrinsicamente ligadas, embora estejam intimamente. O Aparelhamento nos serve à codificação do mundo concreto - que, segundo Flusser, é absurdo. É preciso entender esse aparelhamento; revelar o absurdo.

A discussão em torno das questões como vigilância, violência e aparelhamento é antiga e possui ampla bibliografia. Encontraremos em Platão noções de aparelhamento, de 
vida a partir do dispositivo, através de sua Alegoria da Caverna (um ensaio para o dispositivo cinematográfico, dispositivos de Realidade Virtual). Indivíduos vivendo imersos em tal realidade virtual (e vigiada) de impossível desencanto. O desencanto seria fim da vida, revelação de um programa alienatório com efeitos drásticos - a cegueira pela iluminação e, logo em seguida, a cegueira através do retorno ao escuro do aparelho. O mundo fora da caverna seria ainda perigoso demais, absurdo demais. Sem mediações do absurdo, como enfrentar o que há por vir?

Fabricam-se imagens do mundo, imagens deste por vir. E essas imagens são o rastro do Real, performam sobre o mundo de maneira tão autêntica, que tornam-se o Real. As câmeras, alocadas sobre muros, ditam a realidade, e suas atualizações são como regras. Em algum momento, nos faltará imagens e precisaremos de mais câmeras.

Importa que se entenda que não é por acaso que temos tantas câmeras de vigilância. Ao criar e reproduzir imagens, a humanidade forja memórias: nossa espécie tem por característica possuir raciocínio e arte (techne), ambos relacionando-se à capacidade de registro da humanidade, isso já o dizia Aristóteles em seu Metafísica, "é pela memória que os homens adquirem experiência, porque as inúmeras lembranças da mesma coisa produzem finalmente o efeito de uma experiência única” (1984, p. 11).

O corpo performa a cartilha educativa do aparelho. Anda-se tranquilo enquanto se é vigiado. E ao memorizarmos o fato da vigília, esquecemos, por isso, de que não estamos protegidos. E se temos ainda a chance de pensarmos sobre a presença de câmeras, supomos que existem para frear ações ilícitas: logo, sentimo-nos pouco seguros por estarmos em território que demanda tal aparato de segurança (Segurança e Vigilância andam juntas, mas, de maneira irônica, não implicam-se entre si - uma não sugere a outra).

\section{II}

É importante ainda que não se glorifique a violência. Há ainda coisas mais importantes. O que fazer para não se perder a sensibilidade? Se tudo o que vemos parte do aparelho (a imagem comercial, a imagem adotada pelo hoi polloi), como proteger-se da programação do mesmo? Como manter-se distanciado o suficiente para analisar estas imagens, mas sensível o bastante para não tolerá-las? Se o mundo concreto é absurdo, como retornar ao absurdo? Como fugir de uma mediação que segrega, que desumaniza (a resposta parece simples e assustadora: buscando outras formas de mediação, mais "humanas")? DidiHuberman dirá que "cabe a nós, se quisermos refletir, a tarefa de encontrar sinais de 
inquietação no coração de nossas alegrias presentes, bem como possibilidades de alegria no coração de nossas dores atuais" (2016, pg. 45). Devemos ouvir, pois, as inquietações de nossos corações - ou ainda ouvir o coração das coisas, isto é, no que máquinas e pessoas e eventos tem a nos contar sobre si e sobre nós e como estes contos nos deslocam para um ponto de impessoalidade.

A violação do Outro torna-se suportável após alguns planos. Como isso acontece, por que acontece? O que fazer para não entregar-se? Mais: em que momento nossa própria violação deixa de ser uma preocupação? Em que momento ligamos as câmeras e deixamos nossa individualidade tornar-se espetáculo visível? Damos acesso ao vigilante às nossas imagens e, em troca, ele nos mostra a rua. Nos mostra os carros que passam, quem entra e quem sai de nossos sítios. Não garante nossa segurança, mas garante a impressão de que sabemos de algo do mundo. Flusser afirma em seu "Pós-História" que "as imagens devem ser explicadas, contadas, porque, como toda mediação entre o homem e o mundo, estão sujeitas a dialética interna. Representam o mundo para o homem, mas, simultaneamente, se interpõem entre o homem e o mundo ('vorstellen')" (2001 p. 114). Nossa história será codificada. Imagens que se tornam textos que, mais uma vez, se tornam imagens - a natureza da imagem técnica é esta. Mediações de segunda ordem. Estas mediações irão nos distanciar da ação. Mais uma vez, o caráter de segregação da imagem técnica nos isenta do Real. Programa um espaço seguro onde podemos ver holocaustos sem o menor envolvimento. Toda imagem de vigilância é imagem técnica que elimina uma instância do Real: nos isenta do horror enquanto nos educa. Nossas imagens, nas mãos do funcionário do aparelho servem como testemunho disso: imediatamente são também visualizadas através da rede, somos também espetáculo viral em redes sociais, em programas policiais. Essas imagens dizem menos de quem nós somos e mais do que pode acontecer à quem visualiza a cena. São imagem-didática: pedaço de uma programação.

\section{O QUE VEMOS DE NOSSAS TELAS}




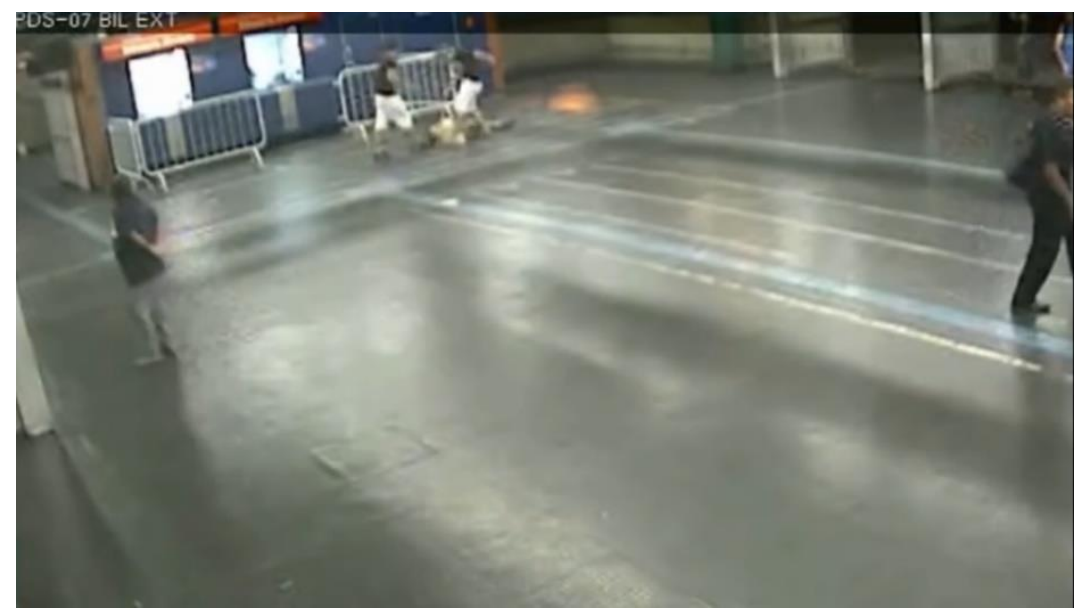

Luiz Ruas é espancado - Fonte: o Autor

A obra sobre a qual este texto fala é uma montagem audiovisual de 10 minutos com diversas imagens de arquivo. Em sua maioria, imagens de câmeras de vigilância: as clássicas câmeras de sistemas de segurança e as recentes câmeras de smartphones. A obra aborda a violência e os processos de naturalização desta através do uso de imagens. "OQUEVEMOS" é uma investigação sobre como imagens de vigilância atuam no que percebemos do mundo, nos domesticando em relação à situações de violência - do modo como sentimos os eventos ao modo como reagimos a isto. Entender como a História parte do aparelho e se volta para ele é uma das propostas. "OQUEVEMOS" analisa o feedback de nossa programação cultural, de como, a partir do que vemos, nos tornamos sujeitos destes vídeos de segurança: corpos com ações marcadas, gestos e emoções pré-programados. Para além de um estudo da imagem, é um estudo sobre o aparelhamento do sujeito contemporâneo.

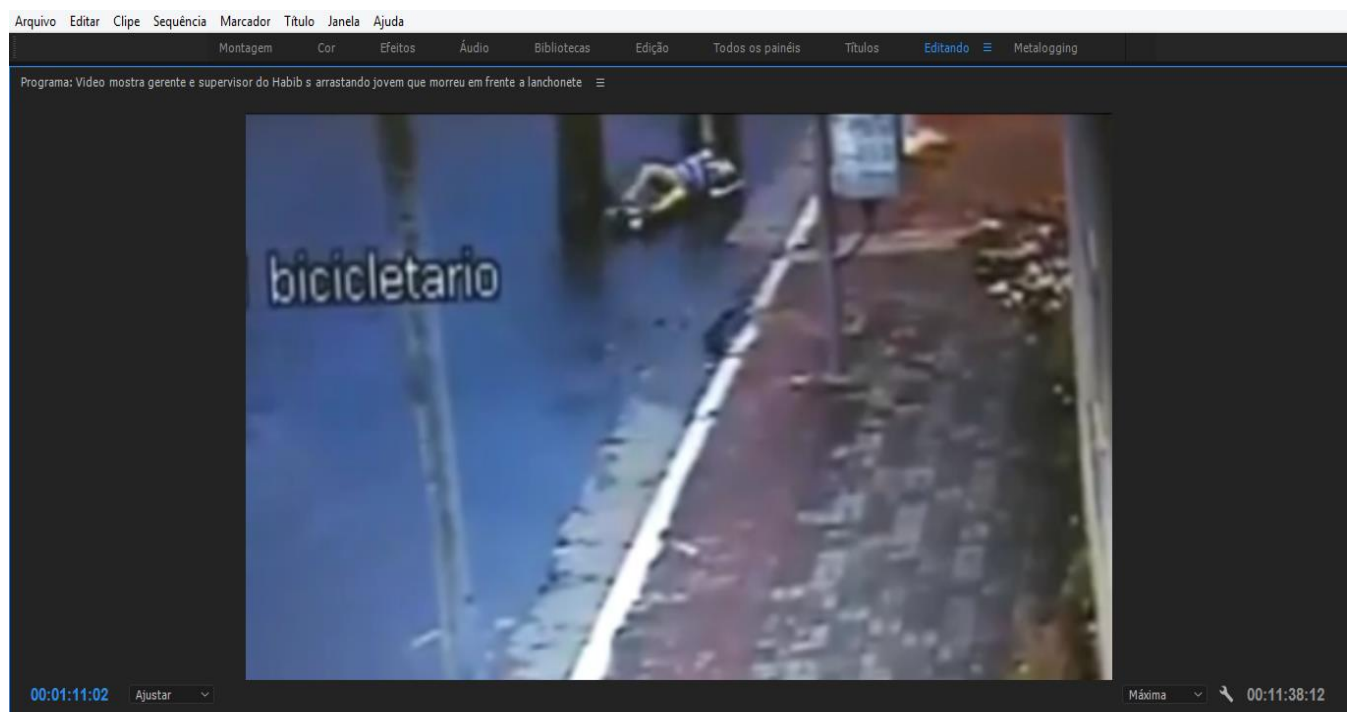

Frame do vídeo da morte de João Victor em processo de edição. - Fonte o Autor

Existem quatro eventos que são vistos e analisados: o vídeo da morte de Luiz Revista Labor Fortaleza/CE, jul/dez 2018 nº 20, Vol. 01, pp. 145-161 ISSN 1983-5000 
Carlos Ruas, ambulante espancado na estação Pedro II, em São Paulo; a dupla de vídeos que mostram momentos antes e após a morte de João Victor, garoto de 13 anos que, segundo laudo médico, sofreu um ataque cardíaco no estacionamento de uma loja do Habbib's, também em São Paulo; o grupo de vídeos filmados por um smartphone do massacre que ocorreu no Complexo Penitenciário Anísio Jobim (Compaj), em Manaus, onde mais de 50 homens foram assassinados brutalmente; por fim, o vídeo, também gravado por um smartphone, onde vemos parte do espancamento da travesti Dandara, que seria morta momentos depois, no Ceará. Farei uma abordagem mais precisa destes vídeos mais tarde. Antes disto, tratarei de explicar sobre como cheguei ao tema do trabalho.

Durante o ano de 2016 aproximei-me das teorias da comunicação de Vilém Flusser. Como estudante de cinema e audiovisual, estar familiarizado com as ideias de Arlindo Machado, Ismail Xavier, entre outros, seria comum. Topar com Flusser seria experiência revolucionária, entretanto. Num curso voltado para o Cinema, principalmente em sua fase contemporânea, o filósofo me distanciaria positivamente do Dispositivo Cinematográfico. Esta experiência me lançou ao desafio de entender a imagem do Vídeo, a imagem digital, a imagem imediata, que me surge diante dos olhos.

Dizer “A Imagem” também não seria exatamente justo. Tenho um objeto, uma imagem por investigar. Investigar essa coisa, isso que é aparência, como já dito, é trabalho de odisseia. Dentro da imagem eletrônica, decido-me por tratar daquilo que hoje em dia é chamado de imagem de vigilância. É sabido que o homem desde sua primeira organização enquanto corpo social dedicou-se à ação da vigilância (Juvenal, entre o século I ou II, colocara em poema uma das pertinentes questões d'A República de Platão: “quem guardará os guardiões?", implicando que a ação da vigilante também necessita ser vigiada). As câmeras de segurança, então, não surpreendem. Há 10 anos não eram tão comuns, mas na passagem dos anos 00 para os anos 10 deste século 21 (principalmente após o atentado às Torres Gêmeas, em Nova Iorque, em 11 de setembro 2001), as câmeras de vigilância tornaram-se necessárias em todo e qualquer espaço. Existem, visíveis ou invisíveis, na maioria dos condomínios, lugares públicos, lojas, transportes coletivos das cidades.

Deixando isto explícito, minha decisão de abordar a imagem da câmera de vigilância a partir de uma visão Flusseriana talvez torne-se mais compreensível. Flusser é um filósofo cujo trabalho nos fez avançar imensamente na compreensão das mídias, dos nossos processos comunicacionais. É nele em que busco os conceitos de aparelho, de programação e jogo. É munido de suas referências que parto em aventura de reconfiguração - de imagens, 
ideias e ações.

A arte possui incrível potência de gerar raciocínio, de gerar emoções. E digo emoção como uma força mobilizadora, diferentemente do que se pode acreditar, a fruição de uma obra artística possui a centelha revolucionária que necessitamos para enfim nos movimentarmos - de um ponto conhecido a outro totalmente novo. "OQUEVEMOS" pretende isto, tragar da arte a possibilidade de uma emoção, fazer com que esta emoção nos desloque, como sugere Didi-Huberman,

[...] uma emoção não seria uma e-moção, quer dizer, uma moção, um movimento que consiste em nos pôr para fora (e-, ex) de nós mesmos? Mas se a emoção é um movimento, ela é, portanto, uma ação: algo como um gesto ao mesmo tempo exterior e interior, pois, quando a emoção nos atravessa, nossa alma se move, treme, se agita, e o nosso corpo faz uma série de coisas que nem sequer imaginamos. (DIDI-HUBERMAN, 2016. p. 26)

Então "OQUEVEMOS” não pôde ser apenas um trabalho escrito. Precisava, sim, da energia da ciência, mas sobretudo da energia da arte. Finalmente encontrei a linguagem e o dispositivo que me interessaria (vídeo-ensaio/vídeo-instalação). Minhas ideias explicadas aqui culminam nessa obra. É possível traduzir conceitos em uma tela, visto que o homem é um animal que pensa e se emociona. Quis acessar o Outro através de um diálogo composto de imagens e sons, algumas palavras.

As referências audiovisuais de "OQUEVEMOS" são diversas. A forma de filmeensaio tão utilizada por Harun Farocki em seus trabalhos foi a principal inspiração para pensar qual direção tomaríamos, eu e a editora. Por diversas questões, não optamos (a equipe) por uma exposição cinematográfica da obra - com isso os nossos referenciais tornaram-se outros, como o artista Antoni Muntadas ou Vito Acconci.

Antoni Muntadas tem uma série de trabalhos onde irá questionar o papel da mídia e das tecnologias de segurança em nossa sociedade. Sobre o escopo artístico de Muntadas, José Roca dirá:

Desde o princípio de seu trabalho artístico, Antoni Muntadas analisa os fenômenos sociais e antropológicos de cada momento, para evidenciar, por meio de uma série de obras de diversos formatos (vídeo, instalação, impressos, internet, intervenções no espaço público etc) a forma como a realidade é configurada e controlada pelos meios de comunicação (Roca. Informação, espaço, controle. 2011, p15).

É dele a obra "Alphaville e outros" (2011), que versa sobre o espaço público e privado, muros e sistemas de segurança. Neste trabalho Muntadas apontará o caráter segregatício dos condomínios fechados e de suas práticas de vigilância. Reunindo imagens do filme "Alphaville” (1965), de Godard - uma ficção científica onde há uma cidade controlada 
pelo robô Alpha 60, que elimina os sentimentos de seus dominados - justapostas ao material publicitário e imagens do condomínio fechado Alphaville, em São Paulo, o artista irá propor o questionamento da formação de nossos espaços urbanos, bem como de que maneira o medo na sociedade contemporânea se apresenta na ubiquidade dos muros e tecnologias de segurança e vigilância.

Muntadas também versará bastante, em suas entrevistas e textos, sobre o papel do artista - um papel que segundo ele é mais de "facilitador":

Às vezes não temos o que fazer, o que já existe pode ser visto de outra forma. Às vezes, tentar mostrar o invisível também é função do artista. Ou aquilo que não se vê, o que está oculto, o que é difícil de se penetrar. Tentar ajudar a ler a imagem ou a relê-la também é importante. (Muntadas. Conferência Fronteiras do Pensamento, 2007).

É seguindo seu pensamento de "reler imagens" que mantenho os apontamentos feitos em "OQUEVEMOS": são imagens parcialmente encobertas, não por camadas físicas, mas por ideias, conceitos e programações. Os dois primeiros blocos de "OQUEVEMOS" funcionam de maneira independente. Um fala do que é visto e o outro do que é encoberto: só no terceiro bloco teremos a junção definitiva dos dois, numa síntese.

Por encaminhar-se para o vídeo, buscamos referências também em um dos trabalhos mais relevantes da história da vídeo-arte: “Centers" (1971), de Vito Acconci, onde o artista aponta em direção à câmera, para si mesmo e para o espectador. Acconci irá utilizar o visor da câmera como um espelho, mantendo sempre o foco da imagem em seu dedo, o que resultará em um gesto direcionado não apenas a si, mas ao exterior. Pode-se dizer que o artista revela o dispositivo entre performer e espectador: entre seu dedo e nossos olhos há uma câmera, um monitor por onde passam as imagens e o projetor de onde elas são geradas.

Claro, os questionamentos em 1971 eram diferentes dos de hoje, mas na energia de "Centers" consigo enxergar a capacidade de gerar uma quebra no olhar do espectador. A atividade de sustentar o dedo diante da câmera é muito parecida com a de sustentar o olhar para esta imagem - há em "OQUEVEMOS" essa necessidade de sustentar o olhar diante das cenas que são mostradas. Não aponto um dedo, mas aponto imagens que também revelam o aparelho e seus vícios.

Tendo esclarecido motivações e inspirações, posso seguir adiante.

O que vem a ser o Aparelho? Aqui eu afirmo que seja uma máquina ou sistema de máquinas que sirva de mediação entre evento e percepção do evento. Em minha pesquisa quero dar a entender que a câmera de vigilância é um aparelho poderoso. Na sequência de 
imagens dedicada às especulações sobre a morte de Luiz Carlos Ruas falo do poder de vigilância dessas câmeras. Redundante, talvez, porém, necessário. Uma câmera de vigilância, por associação é tratada como câmera de segurança. O que percebemos no curto vídeo onde Luiz é espancado é que este conceito é ultrapassado. A câmera de vigilância não nos fornece segurança; na sala do vigilante, em sua caixa-preta, temos o registro das imagens, uma série de eventos é capturado pelas lentes-vigia. Estes eventos serão vistos de forma distanciada. Distante da ação, o vigilante pode escolher o modo como atuar. A primeira noção do poder das imagens que devemos ter é essa: ela nos aparta dos eventos. No caso de Luiz Ruas é essa separação que nos aponta o horror. Temos o espancamento de um homem sendo filmado do princípio ao fim, no entanto a segurança da estação de trem/metrô não é acionada. Essas imagens serão apenas imagens de registro. Saberemos como Luiz morreu, com quantos chutes, de que modo permaneceu deitado no chão. O aparelho irá engolir o ambulante e seus agressores, contará uma história distante de nós e nos mostrará como reagem as pessoas ao redor: 1. com indignação e 2. com passividade. Nós todos já vimos agressões. Sabemos como elas podem acabar e não queremos jamais que alguém nos agrida. $\mathrm{O}$ exemplo pode ficar para o outro. Luiz Ruas é esse exemplo e, mais ainda, os observadores que o cercam.

Teremos nessas imagens uma informação: como pessoas reagem à uma agressão. Outras informações: quantos homens espancaram a vítima, por quanto tempo a espancaram, com que objetos (se houve objetos), se houve uma motivação para a agressão (e a Lei compreende que em certos casos há espaço para uma motivação). O quadro que assistimos é bizarro e injusto. É um espetáculo, ainda. Após sua gravação, a agressão tomou conta de canais de TV e feeds em sites na internet. Nos contou a fábula de um homem chamado de "Índio" que por ter tentado ajudar a travesti de alcunha "Brasil" foi morto sem piedade. O que vemos é a imagem de um crime que não foi impedido.

A câmera que capturou os agressores e vítima deveria ter cumprido a função de segurar, mas, vigiando, nos serviu apenas para registrar. O crime foi solucionado graças à essa e à outras imagens, mas a vigilância aí se tornou ridícula, ineficaz: não impediu a morte de um homem. Mas nos atualizou de uma ação de violência. Através dos telejornais, vimos o mundo perigoso no qual vivemos. Entendemos que a falta de segurança nos ameaça, entendemos que apenas com mais técnicas de proteger propriedades e indivíduos poderemos sair às ruas. Essa imagem conta a história de uma crise e nos informa sobre como o Estado não garante nosso bem-estar. Então o que sobra disso? Exigiremos mais segurança, mais policiamento, mais vigilância. Teremos imagens de tudo, mas jamais impediremos crimes como esse de 
acontecer, por que a imagem cumpre seu papel de anunciar uma crise, mas jamais será a imagem que a eliminará.

Após as imagens brutais de Luiz Ruas, veremos o evento que levou o garoto João Victor à morte. Contrapondo-se à natureza reveladora da cena anterior, na sequência onde vemos alguns momentos antes e após o colapso de João Victor, as câmeras nos faltarão. Teremos dois quadros perversos. Talvez com mais câmeras tivéssemos acesso ao que de fato ocorreu com o garoto, mas não sabemos, não possuímos mais imagens. A sugestão aqui é a de total aparelhamento. $\mathrm{O}$ enquadramento das câmeras captura um estacionamento e um ponto de ônibus. Parte da ação se passa fora do quadro. Temos o início de uma discussão entre um homem e o garoto; temos uma correria sugerida no topo de uma das imagens e logo após o corpo de João sendo carregado de maneira completamente irresponsável e inumana por dois homens. Um terceiro ainda recolhe objetos pelo chão. A imagem aqui nos falta. É cruel demais, as informações da máquina encobrem o evento. Sabemos do humor agressivo do garoto e de um colapso. O que houve? Como João Victor foi reduzido a um corpo sem vida? Não teremos como saber. Testemunhas oculares sugerem agressões, outros afirmam que o garoto estava nervoso ao ponto de ameaçar clientes da franquia de lanchonetes e que, por isso, foi tratado com animosidade, mas não com violência. No que acreditar? Nas imagens do jovem acertando um carro com um pedaço de madeira? Nas imagens de uma correria misteriosa?

A sequência de João Victor tratará de contar como as imagens podem mascarar fatos, construir narrativas distantes do evento. Tudo o que passa pelo Aparelho pode ser fabulado e, portanto, pode ser considerado como ficção: mesmo um evento concreto onde temos testemunhas. A câmera de vigilância deveria ser técnica, funcional. Não deve haver espaço para a dúvida. Se a imagem de Luiz sendo espancado perturba por ser explícita, a de João perturba por mostrar "de menos". E, claro, assumimos aqui que queremos ver algo: um soco, o colapso que leva o garoto ao estado em que o vemos quando está sendo carregado, qualquer coisa que nos mostre um fato. Uma cena de agressão, por menor que seja, nos ajudaria. Uma cena de solidariedade dos homens que carregam o garoto. Mas não há.

\section{III}

Após entender melhor a natureza dúbia da imagem digital, gostaria de me questionar sobre os aparelhos que a fabricam. As câmeras de vigilância migram das paredes e do elevado dos muros para a palma de nossas mãos. Em realidade, não apenas para nossas 
mãos: óculos espiões, canetas, flores espiãs, há toda uma variedade de instrumentos de vigilância e captura da imagem. Hoje, com câmeras minúsculas, nem mais os investigadores precisam se esconder. Como já dito, modelos simples de câmeras de vigilância conversam diretamente com a Rede, de modo que essas tecnologias de produção de imagens há muito já superaram os limites possíveis encontrados por sua "operação". O operador da câmera pode mover a gola de sua camisa e acionar as funções de uma câmera-botão. César Baio, em seu "Máquinas de imagem: arte, tecnologia e pós-virtualidade." fala sobre como a tecnologia e sua entrada na vida íntima das pessoas já não parece um roteiro de ficção científica:

De fato, atualmente, cada vez mais os sistemas computacionais se miniaturizam, se multiplicam e se inserem de maneira mais íntima à nossa vida. No horizonte da ubiquidade computacional, tudo o que nos cerca passa a incorporar microcontroladores, sensores, conexões em rede, telas e projetores. Com isso, roupas, objetos, corpos, edificações, espaços públicos se transformam em plataforma eletrônica para produção e circulação de imagens, sons e textos. (BAIO, 2015, p. 15)

Essa relação íntima que possuímos com as câmeras pode ser observada (de maneira até simplista) em como qualquer modelo de smartphone é projetado não só para produzir imagens, como para compartilhá-las. Temos redes sociais inteiras dedicadas à fotografia, como o Instagram ou o Flickr.

Se a câmera de vigilância das estações de metrô, estacionamentos, CFTVs ao redor do mundo tinham palco televisionado, as câmeras de vigilância dos Smartphones possuem ainda maior plateia: as redes sociais, aplicativos destinados exclusivamente ao compartilhamento de imagens e, claro, os programas televisivos, que, atualizados, já se utilizam de materiais oriundos da Rede.

Por maior difusão, todas as imagens que partem das novas ferramentas de vigilância são virais. Correm em velocidade distinta do evento. O Evento, aqui, é algo que apenas dispara uma questão. Talvez pouco tenha a ver com as imagens geradas dele. As imagens, entretanto, se tornarão este evento. A História partirá do aparelho, será fábula, Ficção, pós-história. O homem que abate outro no presídio em Manaus enquanto é filmado por uma câmera de celular não apenas mata alguém, mas exibe-se em assassinato. Sua performance é direcionada ao Whatsapp, ao Instagram, à viralização; sua facção será considerada "invencível", muito embora saibamos que o crime organizado em nosso país, é extremamente ramificado e tem poderes muito delicados.

A história que partirá do massacre em Manaus não é a de uma briga entre facções rivais que foram capturadas por uma câmera de segurança, mas a encenação de uma disputa 
onde o lado perdedor foi obliterado. A diferença entre a vigilância (captura do real/ vigília) do sistema carcerário e a vigilância do cinegrafista do crime organizado é que a primeira delimita a ação do crime ao campo do presídio, enquanto a segunda nos declara uma invasão através de nossos meios de comunicação. O coração do inimigo foi filmado sendo arrancado não apenas por registro de atitude vitoriosa, mas para disseminação de um conteúdo. Nós estamos aqui, essas imagens dizem, existimos

Uma questão primordial para entendermos como essas imagens nos afetam é perceber que as diversas imagens do mundo contribuíram para a construção desse evento. Das pinturas nos livros dos primeiros exploradores europeus quando estiveram no Novo Mundo, com criaturas bestiais que comem-se entre si, ao super-herói hollywoodiano que crava uma lança no peito de seu inimigo, tudo isto contribuiu para a estética do DVD "Massacre em Manaus - Melhores Momentos", esgotado rapidamente nos camelôs da cidade onde foi gravado. Este talvez seja o principal absurdo que surge do fato de sermos orientados pelo aparelho: perdemos algo de emoção. Ganhamos referências que servirão para que nós mesmos nos tornemos referências.

Existe no gesto assassino algo que nos aparta. A partir dali somos totalmente o Outro. Assistimos. Nós não somos agressores nem agredidos. Talvez por isso estejamos dispostos a ver. A câmera de vigilância desce da parede, está aqui em nossas mãos. Qual poder nos foi dado? Existe na qualidade extensora de nossas percepções na câmera uma força que nos entorpece - é esta força a responsável por nos imergir na "magia" do dispositivo cinematográfico, na atmosfera dispersiva da TV e no jogo ilusório das imagens de vigilância.

McLuhan dirá que a humanidade torna-se rapidamente fascinada por qualquer extensão de si mesma em qualquer material que não seja o dela própria (1964, p. 59), isto pelo efeito narcótico desta extensão - o mesmo entorpecimento pelo qual o jovem Narciso foi dominado quando mirou seu próprio reflexo. A câmera de vigilância, que amplifica nossa capacidade de visão e de registro, seria uma extensão também de nosso sistema nervoso central (e talvez agora haja uma colaboração não hierárquica entre SNC e Tecnologia). Agora entenda-se que nosso corpo suporta uma carga não muito específica, mas limitada, de absorção de fenômenos e poderemos compreender que existe um mecanismo de defesa de nossos próprios órgãos dos sentidos para manter esta hiperabsorção em um nível mais ou menos adequado. Para assimilarmos as imagens do massacre, precisaremos amputar de nossas mentes a probabilidade de nos reconhecermos ali. A domesticação terá papel de extirpar o desconforto causado pelas imagens e, por isso, nos acostumaremos à elas. 
A formalização do mundo concreto não poderia nos deixar ilesos: ao testemunharmos a via-crúcis de Dandara, abrimos alguns de nossos sentidos (como a visão) e fechamos outros (como a empatia, que é mais sentimento que sentido) - esta é a defesa de nosso sistema nervoso central ao estímulo advindo das imagens. A atualização da violência através das câmeras de vigilância trabalha com esses fatores, a amputação de um sentido e o afloramento de outro. Após vermos a dor pela qual Dandara passa, nos anestesiamos e demoramos a nos reconhecer nas imagens (senão como indivíduo - travesti -, como coletivo - espécie humana). McLuhan retomará o tema de Narciso, que não percebe seu reflexo como uma imagem de si próprio, amputando-se do reconhecimento, para tratar disto:

Se Narciso se hipnotiza pela sua própria imagem auto-amputada, há uma boa razão
para o hipnotismo. Há um íntimo paralelo de reações entre as estruturas dos choques
ou traumas físicos e mentais. Uma pessoa que subitamente perde seus entes queridos
e uma que cai de uma altura de poucos metros apresentam ambas sintomas de estado
de choque. A perda da família e a queda física são casos extremos de amputação do
próprio ser. O choque produz um embotamento generalizado ou uma sensibilização
do limiar da percepção. A vítima parece imune à dor e a outros estímulos. [...] A
seleção de um único sentido para estimulação intensa, ou, em tecnologia, de único
sentido "amputado", prolongado ou isolado, é a razão parcial do efeito de
entorpecimento que a tecnologia como tal exerce sobre seus produtores e
consumidores. (MCLUHAN, 1964, pp. 62-63)

Enfim, pode-se entender como tantos consumem imagens intoleráveis: há a construção de uma tolerância que vai apagando alguns de nossos sentidos/sentimentos e estimulando outros. Uma imagem abriria caminho para outra, mesmo que de forma não intencional. $\mathrm{O}$ espetáculo nos orienta em direção a outro evento. A máxima "nada é real, tudo é ficção", de Flusser, vem à tona.

O que pode-se compreender da frase acima? É uma frase que pesa. Em algum momento serve como armadilha (mas quase toda frase é armadilha, visto que as palavras são grávidas de significados). É importante perceber que vamos encarar a realidade a partir de certas apreensões. A armadilha aqui é o uso leviano da frase "nade é real, tudo é ficção" numa esfera em que se legitima horrores. A citação deve desvelar o ficcional. Não encobri-lo.

É Ficção por partir do Aparelho. É Ficção por estar dentro de uma estética da ordem da atuação (representação). Qual o poder que nos foi dado quando nos tornamos vigilantes? O poder de atuar - agir, representar. Somos duplamente atores - triplamente, se consideramos que atuar também significa "tratar por 'tu'", isto é, tratar alguém com familiaridade, o que também realizamos, pois vigiar é ser íntimo. No caso Dandara temos uma amostra disto, dessa atuação. Enquanto os sujeitos a machucam, um deles assume postura policialesca. Coloca os braços para trás, dá ordens e questiona a travesti exatamente Revista Labor Fortaleza/CE, jul/dez 2018 nº 20, Vol. 01, pp. 145-161 ISSN 1983-5000 
como um policial o faria - um mal policial, isto é, o policial que facilmente é apresentado em ficções e mesmo em vídeos de internet. O agressor neste momento é performer, o que ele faz não é exatamente executar uma ação corriqueira, ele atua para a câmera. Quer sair "bem” na gravação.

A atuação também é da ordem do discurso. O que se ouve em cena são ordens para que Dandara se posicione sobre o carrinho de mão (onde mais tarde os agressores a levarão para outro lugar, onde a executarão). Além disso, ouvimos palavras de escárnio como “a 'mundiça' tá de calcinha e tudo" (sic). Este discurso é claro e define as intenções do vídeo: travestis devem temer por suas vidas. No mesmo mês, mais cedo, na mesma cidade (Fortaleza), outra travesti foi agredida: ninguém gravou este abuso. Coube à Dandara ser o corpo agredido, fazer parte da performance macabra de um crime de ódio.

Dandara morreu e o Brasil é o país que mais mata travestis e transexuais no mundo. Em vídeo, em linhas, Dandara faz parte de uma estatística. Mas Dandara não é uma estatística - é uma tragédia. Todos os mortos que aparecem em vídeos logo tornam-se números. A tragédia da câmera de vigilância sobre a esfera pessoal talvez seja essa, o fim da individualidade de caso. Antes de serem engolidos pelo aparelho, os sujeitos mortos fazem parte de uma família, de um grupo de amigos, fazem parte de algo. Após terem suas imagens capturadas, são registros do passado, evidências, estatísticas, exemplos, footage para a realização de curtas universitários, mas não pessoas. As pessoas ficaram para trás e a investigação não chega a elas, mas apenas às consequências de suas mortes. Mais uma vez a emoção é esmagada, o que sobra é tabela científica.

\section{CONSIDERAÇÕES FINAIS}

É impossível atravessar todo o caminho até aqui sem afetar-se. O que sinto quando vejo uma obra de arte como Guernica (1937), de Picasso, certamente não é o que o leitor deste texto sentirá ao fruir a mesma obra. Então: como minha obra afetou a mim? Fica

difícil contemplar a resposta. É possível que, ao final deste texto, o leitor compreenda ainda mais sobre como "OQUEVEMOS" afetou a si e menos ainda sobre como reagi à feitura da obra. De toda forma, não é algo que se perca.

A primeira questão que me surgiu foi de ordem emocional: consigo prosseguir vendo estes vídeos sem enojar-me (e era esta a emoção que sentia, nojo)? Após algum tempo, a questão mudou: consigo prosseguir vendo estes vídeos e continuar me enojando? Após o sentimento de impotência diante das primeiras imagens analisadas (as de Luiz Ruas), 
surpreendi-me acostumado. E, após assistir às decapitações, jogos de futebol com cabeças humanas, pouco reparei nas agressões sofridas pela travesti Dandara. O que eu sugiro em meu trabalho é o papel domesticador das imagens, de como elas podem nos adormecer e atualizar a violência em nossos ambientes virtuais. Havia acontecido comigo.

Mas por acontecer exatamente comigo não significa que acontecerá com qualquer outro espectador. A segunda questão foi a de ordem prática: como montar uma obra que fale sobre o que quero falar e que funcione de alguma maneira parecida como funcionou comigo? Foram horas de trabalho com a montadora Mariana Gomes, que assistiu à uma grande parte acervo do que resolvemos chamar de "horríveis vídeos de pessoas morrendo". Com a ajuda da orientação do professor Yuri Firmeza, encontramos dentro de nossa técnica a estética que poderia nos ajudar a passar a mensagem da maneira que sonhávamos passar.

Para resolver a primeira questão, resolvi distanciar-me do que assistia. Esta talvez seja uma palavra-chave do trabalho, distanciamento. Consegui recuperar a emoção, mas não apenas reassistindo os vídeos. Tive de procurar saber mais sobre as pessoas que morriam diante de mim, tive de pensar milhares de vezes que eram seres humanos exatamente iguais a mim. Vindo de uma tradição familiar cristã, a maior tarefa foi fugir do sentimento de culpa e aceitar o sentimento de responsabilidade: pautava meu trabalho sobre figuras mortas, sobre algo de miséria da espécie humana - como tratar disto e não ser um artista viciado? Como falar dessas figuras e ainda assim manter o respeito por elas? Dediquei-me à tarefa de, na segunda questão, a montagem, incomodar. Não pelo espetáculo, não pelo fornecimento de imagens cruéis (isto é um trabalho que não precisa de agentes como eu, as imagens espalhamse pela internet e programas policiais de maneira abundante). Incomodar para apontar.

Acredito no potencial benéfico de nossos aparelhos produtores de imagem, do potencial artístico deles, mas também no potencial destrutivo, no potencial domesticador. Desta maneira, do início de minha pesquisa até agora, enquanto escrevo, sei que fui afetado. É necessário que olhemos através das estatísticas, dos fragmentos de informação. Não de maneira paranoica. Flusser dirá que existem duas formas sintomáticas de estupidez no mundo pós-histórico, este dominado pelas imagens técnicas que surgem de nossos aparelhos: "a estupidez dos aparelhos programadores" e a "estupidez dos bárbaros destruidores de aparelhos" (p190). Se o indivíduo domesticado é funcionário do aparelho programador, o paranoico figura como um bárbaro destruidor de aparelhos.

Não busco a destruição. O que busco é retornar ao ponto onde nos emocionamos e subvertemos o que a programação de nossos aparelhos nos sugere. "OQUEVEMOS" pode ser 
visto tanto de maneira privada, em casa, quanto em um museu - seu dispositivo seria o mesmo que temos em nossas mãos diariamente: um smartphone ou tablet, um computador pessoal, rodando infinitamente imagens que escapam do feedback forçado por nossa programação, justamente por apontarem a alienação causada por esta.

Há um mal-estar em nossa sociedade. Vários grupos já percebem como certas imagens se impõem diante de nós - padrões de beleza, padrões de consumo. Temos buscado o Outro com mais força do que nunca. Ainda assim nos mantemos apartados. Existe uma lógica perversa nisto sobre a qual dificilmente conseguirei me debruçar neste trabalho, que é a lógica da produtividade se impondo à inventividade, que é a do encarceramento se impondo à filosofia, a lógica da mercadoria que supera a arte. Essa lógica pode ser observada cruamente no material que utilizei para realizar "OQUEVEMOS". É um material difícil, absurdo, mas necessário - exatamente por suas duas primeiras características. Tudo o que pudemos ver passou por um tipo de "linha de produção" onde foram inseridas as peças que nos fazem perder o acesso ao Outro. Pude "tomar os meios de produção" e reorganizar a fábrica; pude trocar peças, pôr em primeiro plano a ação do pensamento, a emotividade da arte.

Não posso concluir um trabalho como este a falar: os resultados são x e y. Os resultados para mim são dois fantasmas, um texto e uma montagem audiovisual. Quero que ela chegue ao Outro da mesma forma que chegou a mim. Não posso afirmar que chegará, mas posso afirmar que tentei. Foram quatro anos e meio estudando sobre como contar algo de maneira audiovisual - existem os formalismos próprios para isto, e à estas regras respeitei ou desrespeitei completamente, mas com carinho. A História parte, sim, do Aparelho. O fato de minha obra existir apenas virtualmente me faz um pouco mais crente diante desta frase. Por vezes pensei poder afirmar que sei disto, mas agora apenas creio. Crer foi o bastante para me emocionar e para realizar tudo o que realizei aqui.

\section{REFERÊNCIAS BIBLIOGRÁFICAS}

ARAÚJO, Marcelo Matos et al. Muntadas: informação, espaço, controle. São Paulo: Pinacoteca do Estado de São Paulo, 2011.

ARISTÓTELES. Metafísica. São Paulo: Editora Abril, 1984.

BAUDRY, Jean-Louis. Cinema: efeitos ideológicos produzidos pelo aparelho de base. In. XAVIER, Ismail (org.) A experiência do cinema. Rio de Janeiro: Edições Graal: Embrafilmes, 1983.

COUCHOT, Edmond. A tecnologia na arte: da fotografia à realidade virtual. Traduzido por Sandra Rey. Porto alegre: Editora da UFRGS, 2003. 
DIDI-HUBERMAN, Georges. Que emoção! Que emoção? São Paulo: Editora 34. 2016.

DUBOIS, Philippe. Cinema, Vídeo, Godard. Traduzido por Mateus Araújo Silva. São Paulo: Cosac Naify, 2004.

FLUSSER, Villém. Pós-História: vinte instantâneos e um modo de usar. São Paulo: Annablume, 2011.

LABAKI, Amir (org.). A Verdade de cada um. São Paulo: Cosac Naify, 2015.

MACHADO, Arlindo. A televisão levada a sério. São Paulo: Editora Senac São Paulo, 2014.

MACHADO, Arlindo. O Sujeito na Tela: Modos de enunciação no cinema e no ciberespaço. São Paulo: Paulus, 2007.

MCLUHAN, Marshall. Os meios de comunicação como extensões do homem. Tradução de Décio Pignatari. São Paulo: Cultrix, 2007.

MERLEAU-PONTY, Maurice. O Olho e o Espírito. São Paulo: Cosac Naify, 2013.

PLATÃO. A República. São Paulo: EDIPRO. 2012.

SANTOS, César A. Baio. Máquinas de imagem: arte, tecnologia e pós-virtualidade. São Paulo: Annablume, 2015.

SOUSA, George Ulysses R. OQUEVEMOS. Video-Ensaio disponível em https://www.youtube.com/watch?v=_6E2qksoHuI\&app=desktop $(17 / 10 / 2018)$. 